\title{
Disease-controlling effect of a novel fungicide pyribencarb against Botrytis cinerea
}

\author{
Makiichi TAKAGAKI*, Satoshi KATAOKA, Kenichi KIDA, Ichiro MiURA ${ }^{\dagger}$, \\ Shunichirou FUKUMOTO ${ }^{\dagger \dagger}$ and Ryuji TAMAI ${ }^{\dagger \dagger}$ \\ Life Science Research Institute, Kumiai Chemical Industry Co., Ltd., 3360 Kamo, Kikugawa, Shizuoka 439-0031, Japan \\ ${ }^{\dagger}$ Tohoku Research Center, Kumiai Chemical Industry Co., Ltd., 100 Yamanokami, Misato, Miyagi 987-0003, Japan \\ ${ }^{\dagger}$ K-I Chemical Research Institute Co., Ltd., 408-1 Shioshinden, Iwata, Shizuoka 437-1213, Japan
}

(Received June 3, 2009, Accepted October 23, 2009)

\begin{abstract}
Pyribencarb, methyl \{2-chloro-5-[(E)-1-(6-methyl-2-pyridylmethoxyimino)ethyl]benzyl $\}$ carbamate, is a novel fungicide having excellent activity against a wide range of plant pathogenic fungi, especially gray mold diseases caused by Botrytis cinerea. Pyribencarb exhibited not only a preventive effect but also a curative effect. When spraying was performed $48 \mathrm{hr}$ after inoculation (after visible symptoms appeared), pyribencarb also showed strong inhibitory activity against lesion development by cucumber gray mold that was significantly superior to its preventive activity. Experiments in the greenhouse demonstrated good translaminar, rain fastness and residual activities, resulting in pyribencarb's high performance in the field. Pyribencarb was effective to control eggplant gray mold and kidney bean gray mold at $100-200 \mu \mathrm{g} / \mathrm{ml}$ in field trials. (C) Pesticide Science Society of Japan
\end{abstract}

Keywords: pyribencarb, Botrytis cinerea, gray mold, disease-controlling activity.

\section{Introduction}

Pyribencarb, methyl \{2-chloro-5-[(E)-1-(6-methyl-2-pyridylmethoxyimino)ethyl]benzyl $\}$ carbamate (Fig. 1) is a novel fungicide from a new chemical class based on the benzylcarbamate moiety, invented and currently under development by Kumiai Chemical Industry Co., Ltd. and Ihara Chemical Industry Co., Ltd. ${ }^{1)}$ Although the precise mode of action of pyribencarb remains to be elucidated, this compound inhibits the respiration of fungal pathogens. ${ }^{2)}$ Pyribencarb is active against a wide range of economically important fungal

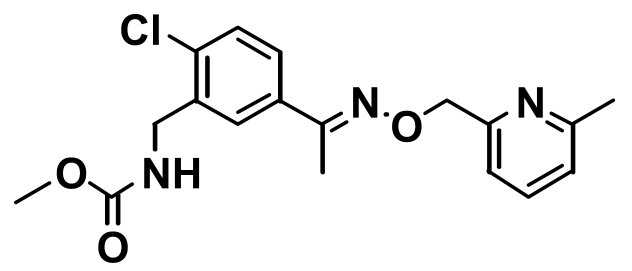

Fig. 1. Chemical structure of pyribencarb.

\footnotetext{
* To whom correspondence should be addressed.

E-mail: m-takagaki@kumiai-chem.co.jp

Published online December 22, 2009

(C) Pesticide Science Society of Japan
}

pathogens $^{3,4)}$ and is especially efficacious against gray mold diseases caused by Botrytis cinerea and sclerotinia rot diseases caused by Sclerotinia sclerotiorum.

Gray mold caused by B. cinerea is an economically important disease worldwide, and the development of resistance to conventional fungicides has become evident and caused practical problems. Pyribencarb exhibited excellent inhibitory activity against strains of $B$. cinerea resistant to benzimidadole fungicides and dicarboximide fungicides. ${ }^{2)}$ These results suggest that pyribencarb can be a proper candidate to replace these fungicides in areas where resistant strains are dominant. In addition, pyribencarb is expected to prevent simultaneous diseases owing to its broad spectrum of disease control.

This paper describes some of the biological activities of pyribencarb in greenhouse trials against cucumber gray mold, and also describes the controlling effect of pyribencarb in the field against gray mold in eggplant and kidney bean.

\section{Materials and Methods}

\section{Chemicals and pathogens}

Pyribencarb was synthesized by Ihara Chemical Industry Co., Ltd. and formulated as a 40\% WG. Mepanipyrim (40\% SC), fenhexamid (50\% WG), azoxystrobin (20\% SC), iprodione (50\% WP), thiophanate-methyl $(70 \% \mathrm{WP})$, boscalid $(50 \%$ DF), procymidone (50\% WP), fludioxoni (20\% SC) and fluaz- 
inam $(50 \% \mathrm{WP})$ were purchased from commercial sources.

Isolate (Kumiai S-1) of B. cinerea was grown and maintained on potato-dextrose agar (PDA; Nissui Pharmaceutical Co., Ltd., Tokyo, Japan) plates at $20^{\circ} \mathrm{C}$, and was illuminated with near-ultraviolet light (FL15B; Toshiba Lighting \& Technology Co., Tokyo, Japan) for 2-3 days to induce spore formation.

\section{Greenhouse trials}

2.1. Preventive, curative and lesion development inhibitory effects

Cucumber seedlings (Cucumis sativus cv. Sagami-hanjiro; Asahinohen, Japan) were grown in $6 \mathrm{~cm}$ plastic pots filled with fertilized granulated soil (Kureha Corporation, Tokyo, Japan) in non-sterile conditions to the cotyledon stage. Seedlings were sprayed with $10 \mathrm{ml}$ per pot of test fungicide solutions or distillated water (control) supplemented with $0.02 \%$ spreader Kumiten $^{\circledR}$; Kumiai Chemical Industry Co., Ltd.). Spraying was performed $3 \mathrm{hr}$ prior to inoculation for the preventive effect assay, $24 \mathrm{hr}$ after inoculation (before symptoms appeared) for the curative effect assay or $48 \mathrm{hr}$ after inoculation (after visible symptoms appeared) for the lesion development inhibitory assay, respectively. For inoculation, conidial spores of $B$. cinerea were suspended in medium containing $0.3 \%$ yeast extract and $2 \%$ glucose, ${ }^{5,6)}$ and paper discs (6 $\mathrm{mm}$ in diameter, thick type; Toyo Roshi Kaisya, Ltd.) dipped in the spore suspension $\left(1 \times 10^{6}\right.$ spores $\left./ \mathrm{ml}\right)$ were placed in the center of cotyledons. The inoculated plants were incubated in a chamber with high humidity at $20^{\circ} \mathrm{C}$. Three days after inoculation, the lesion diameter was measured and the disease control effect of the test fungicide was assessed as a percentage of reduced lesion size in comparison with untreated plants. Lesion development inhibitory activity was calculated by the following equation. These tests were conducted with three replications

Control value $(\%)=(1-$ developed lesion length of the fungicide-treated leaf/developed length of the untreated leaf) $\times 100$

Developed lesion length=lesion diameter of final observation of each leaf-lesion diameter observed immediately before treatment of each leaf.

\subsection{Rain fastness and residual activity}

Cucumber seedlings at the cotyledon stage were sprayed with the test chemical solutions and distillated water, prepared by the same method as in Section 2.1. For the rain fastness activity assay, treated plants were exposed to $40 \mathrm{~mm} / \mathrm{hr}$ rain for 2 hr using artificial equipment after the spray deposit had dried in air for $3 \mathrm{hr}$. For the residual activity assay, the treated plants were kept in the greenhouse for 7 days. The test plants were inoculated and evaluated using the same methods as described in Section 2.1. The $\mathrm{EC}_{50}\left(\mathrm{R}_{1}\right)$ was calculated from control values for the plot of artificial rainfall treatment, the $\mathrm{EC}_{50}\left(\mathrm{R}_{2}\right)$ from control values from the plot kept for 7 days in the greenhouse, and the $\mathrm{EC}_{50}(\mathrm{C})$ from control values from the plot without these treatments. The $\mathrm{EC}_{50}$ ratio was calculated as follows:

$$
\mathrm{EC}_{50} \text { ratio }=\mathrm{EC}_{50}\left(\mathrm{R}_{1}\right) \quad \text { or } \quad \mathrm{EC}_{50}\left(\mathrm{R}_{2}\right) / \mathrm{EC}_{50}(\mathrm{C})
$$

When " $\mathrm{R}_{1}$ " or " $\mathrm{R}_{2}$ " is equal to " $\mathrm{C}$ ", then the $\mathrm{EC}_{50}$ ratio is 1.0 , indicating that the effect dose was not influenced by rain or holding for 7 days. Data presented are the means of three replications.

\subsection{Translaminar and systemic action}

For the translaminar action assay, kidney bean seedlings (Phaseolus vulgaris cv. Yukitebou; Tokachinoukyoren, Japan) at the primary leaf stage were grown in $9 \mathrm{~cm}$ unglazed pots. Kidney bean leaves were more easily inoculated with $B$. cinerea on the abaxial surface due to the presence of fewer hairs than cucumber leaves. The adaxial surfaces of kidney bean seedling leaves were sprayed with the test fungicide using $0.02 \%$ spreader $\left(\right.$ Kumiten $\left.^{\circledR}\right)$. After 3 days, the abaxial surface of the treated leaves was inoculated, and evaluated using the same methods as described in Section 2.1.

In the systemic action test, cucumber seedlings were prepared by the same method as described in Section 2.1. Cucumber seedlings at the cotyledon stage in soil were drenched with 31 of fungicide solution per square meter. After 3 days, the leaves of the treated plants were inoculated and evaluated using the same methods as described in Section 2.1. Three replications were made for each treatment.

\section{Field trials}

\subsection{Eggplant gray mold}

Eggplant seedlings (Solanum melongena cv. Kokuyo; Takii Seed Company, Japan) were planted in a vinyl house at our institute. The trial was laid out with a randomized block design with 3 replicates of 3 plants per pot. After the first application, PDA plates of sporulating $B$. cinerea were hung in the test field as the inoculum. Test fungicides containing $0.02 \%$ spreader $\left(\right.$ Kumiten $\left.^{\circledR}\right)$ were applied 3 times in total at 7-day intervals as a spray at a rate of 2001/10a. The effect of the test fungicides was evaluated as a percentage of diseased flowers and fruits 7 days after the third application.

\subsection{Kidney bean gray mold}

Kidney bean seeds were sowed in the field at our institute. The trial was laid out with a randomized block design with 3 replicates of 75 plants per pot. After the first application, PDA plates of sporulating $B$. cinerea were hung in the test field as the inoculum. Test fungicides containing $0.02 \%$ spreader $\left(\right.$ Kumiten $^{\circledR}$ ) were applied 3 times in total at 9-day intervals as a spray at a rate of $1001 / 10 \mathrm{a}$. The effect of the test fungicides was evaluated as a percentage of the diseased pods 8 days after the third application. 


\section{Results and Discussion}

\section{Greenhouse tests}

\subsection{Preventive, curative and lesion development in- hibitory effects}

Pyribencarb exhibited excellent preventive (Fig. 2), and curative (Fig. 3) activities against cucumber gray mold. Pyribencarb also showed excellent inhibitory activity against lesion development when the test fungicide was applied after visible symptoms had appeared (Fig. 4). In these tests, the effect of pyribencarb was superior to the 6 standard fungicides.

In preventive applications, fenhexamid and boscalid exhibited a good effect $\left(\mathrm{EC}_{50}\right.$ values of $2.13 \mu \mathrm{g} / \mathrm{ml}$ and $0.80 \mu \mathrm{g} / \mathrm{ml}$, respectively), but these activities were inferior to pyribencarb $\left(\mathrm{EC}_{50}=0.55 \mu \mathrm{g} / \mathrm{ml}\right)$. The trends of curative and inhibitory activity toward lesion development for each fungicide were similar.

For many fungicides, these curative activities are assumed to be inferior to preventive activities. Benthiavalicarb-isopropyl, an oomycete fungicide, had not only strong preventive but also strong curative effects; however, its curative effect did not reach its preventive effect. ${ }^{7)}$ Similar activity trends were reported for other fungicides. ${ }^{9-11)}$ Pyribencarb showed excellent curative activity ( $c a .80 .4 \%$ at $3 \mu \mathrm{g} / \mathrm{ml}$ ) and inhibitory activity ( $c a .88 .5 \%$ at $3 \mu \mathrm{g} / \mathrm{ml}$ ) against lesion development, superior to its preventive activity ( $c a .72 .1 \%$ at $3 \mu \mathrm{g} / \mathrm{ml}$ ); therefore, the performance by pyribencarb was marked. Since pyribencarb markedly inhibited mycelial growth of $B$. cinerea (MIC: $0.1 \mu \mathrm{g} / \mathrm{ml}, \mathrm{EC}_{50}: 0.006 \mu \mathrm{g} / \mathrm{ml}$ ), its high curative and eradicant activities could be ascribed to its strong mycelial growth inhibition. These results indicate that pyribencarb may be applied, not only in advance, but also at the early stages of disease development.

\subsection{Rain fastness and residual activity}

The rain fastness of pyribencarb was almost equivalent to that of the standard fungicide mepanipyrim, as shown in Fig. 5. Pyribencarb was also persistent when examined with cucumber seedling incubation for 7 days in a greenhouse. Pyribencarb resulted in high suppression of disease development at

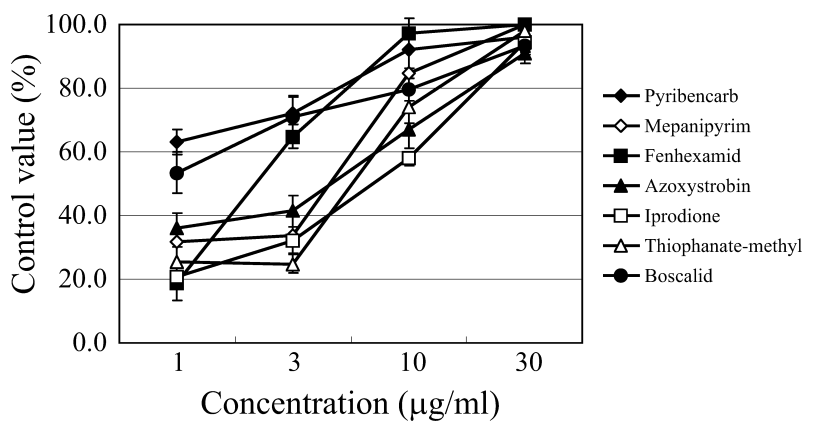

Fig. 2. Preventive effect of pyribencarb on cucumber gray mold. Inoculation was performed immediately after the spray deposit had dried. Vertical bars represent standard deviations of the mean $(n=3)$.

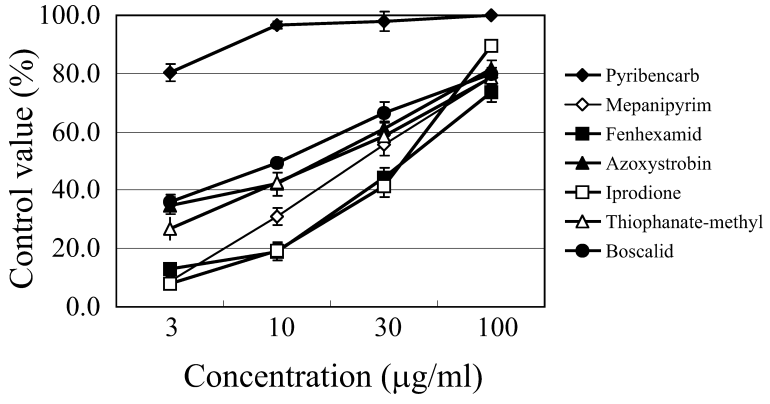

Fig. 3. Curative effect of pyribencarb on cucumber gray mold. Test fungicides were applied $24 \mathrm{hr}$ after inoculation (before lesions started to emerge). Vertical bars represent standard deviations of the mean $(n=3)$.

levels equivalent to mepanipyrim. These results clearly indicate that loss of pyribencarb activity was relatively small, and pyribencarb will demonstrate full control in the field.

\subsection{Translaminar and systemic action}

Pyribencarb exhibited good translaminar activity (adaxial to abaxial), almost equal to iprodione (Fig. 6). This property may have contributed to the good control obtained under practical field conditions described later, because spray solutions are not always uniformly sprayed onto leaves. Pyribencarb also showed systemic translocative activity from root to leaves at $1000 \mu \mathrm{g} / \mathrm{ml}$, although its effect was slightly inferior to that of iprodione (Fig. 7).

In controlled-environment conditions, pyribencarb exhibited effective preventive and curative activities, inhibited lesion development, and showed rain fastness and residual activities that were equivalent to or better than those of the standard reference fungicides.

These properties could lead to a high level of control by pyribencarb in the field.

\section{Field trials}

\subsection{Eggplant gray mold}

We tested the effect of pyribencarb on eggplant and kidney

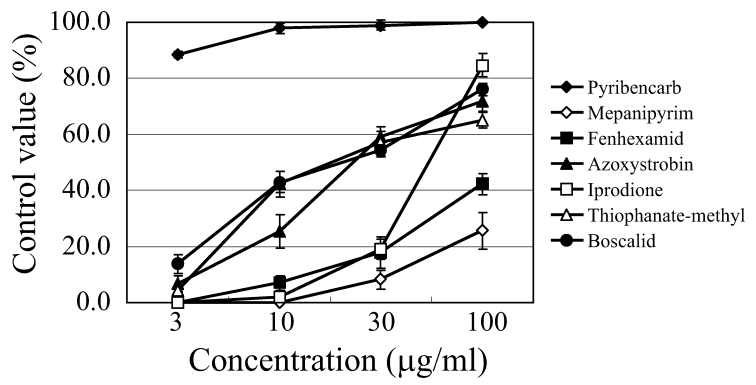

Fig. 4. Effect of pyribencarb on lesion development of cucumber gray mold. Test fungicides were applied $48 \mathrm{hr}$ after inoculation (after lesions emerged). Vertical bars represent standard deviations of the mean $(n=3)$. 


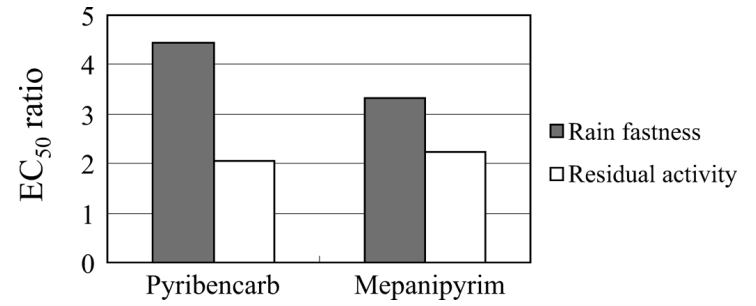

Fig. 5. Rain fastness and residual activity of pyribencarb against cucumber gray mold. The $\mathrm{EC}_{50}$ ratio was calculated as described in Materials and Methods.

bean gray mold in the field.

The effect of pyribencarb against eggplant gray mold was evaluated by 3 applications at 7-day intervals (Table 1). Symptoms on eggplant initially appeared 1 day after the second application on petals in the untreated control. In this trial, infection pressure was heavier and diseased flowers and fruits were $52.7 \%$ in the untreated control at evaluation. Pyribencarb at 100 and $200 \mu \mathrm{g} / \mathrm{ml}$ exhibited good control of the disease. The effect of pyribencarb at $100 \mu \mathrm{g} / \mathrm{ml}$ against eggplant gray mold was equal to that of procymidone at $500 \mu \mathrm{g} / \mathrm{ml}$, but was slightly superior to that of fludioxonil at $200 \mu \mathrm{g} / \mathrm{ml}$. The effect of pyribencarb at $200 \mu \mathrm{g} / \mathrm{ml}$ was slightly superior to that of all reference fungicides. There were no observed phytotoxic symptoms in the tested eggplants under the trial conditions when pyribencarb was applied at $100-200 \mu \mathrm{g} / \mathrm{ml}$.

\subsection{Kidney bean gray mold}

The effect of pyribencarb on kidney bean gray mold was evaluated by 3 applications at 9 -day intervals (Table 1). Symptoms on kidney beans initially appeared concomitantly with the second application on petals in the untreated control. In this trial, infection pressure was moderate, and diseased pods were $21.0 \%$ in the untreated control at evaluation. Pyribencarb at 100 and $200 \mu \mathrm{g} / \mathrm{ml}$ gave good disease control without any phyotoxicity. The effect of pyribencarb at $100 \mu \mathrm{g} / \mathrm{ml}$ against kidney bean gray mold was equal to that of procymidone at $500 \mu \mathrm{g} / \mathrm{ml}$, but was slightly superior to that of fluazinam at $500 \mu \mathrm{g} / \mathrm{ml}$. The effect of pyribencarb at $200 \mu \mathrm{g} / \mathrm{ml}$ was slightly superior to that of all reference fungicides.

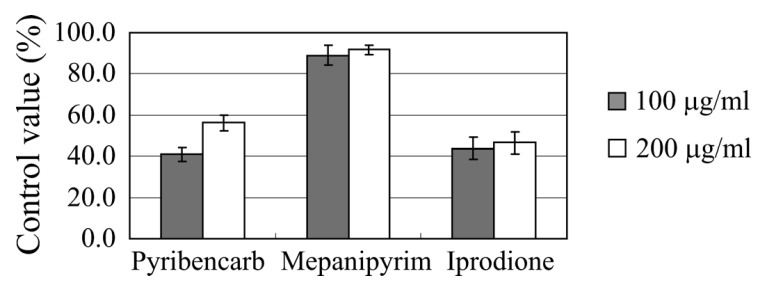

Fig. 6. Translaminar activity of pyribencarb against kidney bean gray mold. Test fungicides were applied only to the adaxial surface of kidney bean leaves. After 3 days, inoculation was carried out on the abaxial surface. Vertical bars represent standard deviations of the mean $(n=3)$.

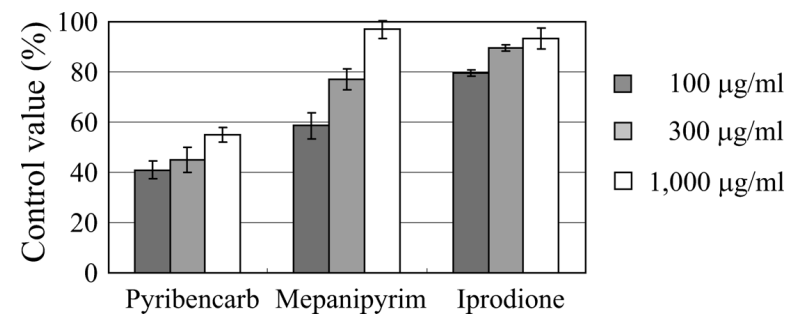

Fig. 7. Systemic activity of pyribencarb from roots against cucumber gray mold. Test fungicide was applied to the soil in a drench 3 days before inoculation. Vertical bars represent standard deviations of the mean $(n=3)$.

The control of gray mold by fungicide has been adversely affected by the development of resistance, and several resistant strains have already been reported against anilinopyrimidine, phenylpyrrole, hydroxyanilide, benzimidazole, dicarboximide and phenylcarbamate fungicides. ${ }^{12,13)}$ Pyribencarb demonstrated a good effect against strains resistant to benzimidadole fungicides, dicarboximide fungicides and both benzimidadole and $\mathrm{N}$-phenylcarbamate fungicides (diethofencarb), as well as strains sensitive to these fungicides, ${ }^{2)}$ suggesting that pyribencarb is an appropriate candidate to replace these fungicides in areas where resistant strains are dominant.

To conclude, the fungicidal and disease-controlling activities of pyribencarb are characterized by its preventive, curative, translaminar, and residual activities, its inhibitory activity toward lesion development, and its rain fastness. The most striking feature of pyribencarb was thought to be its stronger disease-controlling activity after the appearance of visible symptoms compared with its preventive effects. These results suggest that the biological properties of pyribencarb contribute to its excellent ability to control gray mold on various crops in the field. Since pyribencarb exhibited a good effect

Table 1. Effect of pyribencarb against eggplant and kidney bean gray mold

\begin{tabular}{|c|c|c|c|}
\hline Compound & $\begin{array}{l}\text { Concentration } \\
\qquad \mu \mathrm{g} / \mathrm{ml}\end{array}$ & $\begin{array}{l}\text { Eggplant gray } \\
\text { mold \% of } \\
\text { diseased flowers } \\
\text { and fruits }\end{array}$ & $\begin{array}{l}\text { Kidney bean } \\
\text { gray mold \% } \\
\text { of diseased } \\
\text { pods }\end{array}$ \\
\hline \multirow[t]{2}{*}{ Pyribencarb } & 100 & $9.8 \mathrm{bc}$ & $5.3 \mathrm{~b}$ \\
\hline & 200 & $3.4 \mathrm{c}$ & $3.7 \mathrm{bc}$ \\
\hline Procymidone & 500 & $12.3 \mathrm{~b}$ & $4.6 \mathrm{~b}$ \\
\hline Fludioxonil & 200 & $16.8 \mathrm{~b}$ & $\mathrm{NT}^{a)}$ \\
\hline Fluazinam & 500 & NT & $7.8 \mathrm{~b}$ \\
\hline Untreated control & & $52.7 \mathrm{a}$ & $21.0 \mathrm{a}$ \\
\hline
\end{tabular}

a) NT: not tested. Figures (\%) followed by a common letter do not differ significantly according to Duncan's multiple range test $(p<0.05)$. 
against $B$. cinerea in vivo, our next investigation goal is to elucidate the intrinsic fungicidal activities in vitro and mode of action of pyribencarb.

\section{REFERENCES}

1) M. Ozaki, S. Fukumoto, R. Tamai, N. Yonekura, K. Ikegaya, T. Kawashima, J. Sakai, N. Muramatu, M. Takagaki and K. Nagayama (Kumiai Chemical Industry Co., Ltd. and Ihara Chemical Industry Co., Ltd.): WO 01/10825 A1 (2001).

2) S. Kataoka, M. Takagaki, T. Nakano, K. Kaku, S. Fukumoto, S. Watanabe, K. Nozaki and T. Shimizu: 11th IUPAC International Congress of Pesticide chemistry, Book of Abstracts (2), 138 (2006).

3) M.Takagaki, M. Kawata, S. Fukumoto and I. Miura (Abstract): Jpn. J. Phytopathol. 71, 256 (2005) (in Japanese).

4) M. Takagaki, S. Kataoka, S. Fukumoto, H. Ishii, J. Yamaguchi, M. Inada, M. Kansako and K. Nozaki (Abstract.): Jpn. J. Phytopathol. 72, 274 (2006) (in Japanese).

5) K. Ko, K. Akutsu, Y. Kobayashi, Y. Om, T. Watanabe and T.
Misato: Ann. Phytopathol. Soc. Jpn. 47, 228-233 (1981).

6) K. Akutsu, Y. Kobayashi, Y. Matsuzawa, T. Watanabe, K. Ko and T. Misato: Ann. Phytopathol. Soc. Jpn. 47, 234-243 (1981).

7) Y. Miyake, J. Sakai, M. Shibata, N. Yonekura, I. Miura, K. Kumakura and K. Nagayama: J. Pestici. Sci. 30, 390-396 (2005).

8) I. Miura and S. Maeno: J. Pestic. Sci. 32, 106-111 (2007).

9) M. Haramoto, H. Yamanaka, H. Hosokawa, H. Sano, S. Sano and H. Otani: J. Pestici. Sci. 31, 116-122 (2006).

10) D-S. Kim, S-J. Chun, J-J. Jeon, S-W Lee and G-H. Joe: Pest Manag Sci. 60, 1007-1012 (2004).

11) S. Jogaiah, S. Mitani, A. K. Nagaraj and S. H. Shekar: Pest Manag. Sci. 63, 722-727 (2007).

12) P. Leroux, R. Fritz, D. Debiue, C. Albertini, C. Lanen, J. Bach, M. Gredt and F. Chapeland: Pest Manag. Sci. 58, 876-888 (2002).

13) C. K. Myresiots, G. S. Karaoglanidis and K. Tzavella-Klonari: Plant Dis. 91, 407-413 (2007). 